\title{
Autotrophic Nitrogen Removal in a Membrane-Aerated Biofilm Reactor Under Continuous Aeration: A Demonstration
}

\author{
Kevin R. Gilmore, ${ }^{1, * \dagger}$ Akihiko Terada, ${ }^{2,+}$ Barth F. Smets, ${ }^{2}$ Nancy G. Love, ${ }^{3}$ and Jay L. Garland ${ }^{4, \#}$ \\ ${ }^{1}$ Department of Civil and Environmental Engineering, Virginia Polytechnic Institute and State University, Blacksburg, Virginia. \\ ${ }^{2}$ Department of Environmental Engineering, Technical University of Denmark, Lyngby, Denmark. \\ ${ }^{3}$ Department of Civil and Environmental Engineering, University of Michigan, Ann Arbor, Michigan. \\ ${ }^{4}$ Dynamac Corporation, Kennedy Space Center, Florida.
}

Received: June 1, $2012 \quad$ Accepted in revised form: August 15, 2012

\begin{abstract}
This work describes the successful coupling of partial nitrification (nitritation) and anaerobic ammonium oxidation in a membrane-aerated biofilm reactor (MABR) with continuous aeration. Controlling the relative surface loadings of oxygen versus ammonium prevented complete nitrite oxidation and allowed anaerobic ammoniumoxidizing bacteria (AnaerAOB) to develop and be retained for $>250$ days. Daily autotrophic nitrogen removal of $1.7 \mathrm{~g} \mathrm{~N} / \mathrm{m}^{2}$ (75\% of influent $\mathrm{N}$ load) was achieved at an oxygen/nitrogen surface loading ratio of 2.2, with up to $85 \%$ of the influent $\mathrm{N}$ proceeding through AnaerAOB. During early nitritation, nitrogen oxide $\left(\mathrm{NO}_{(\mathrm{g})}, \mathrm{NO}_{2(\mathrm{~g})}\right.$, and $\left.\mathrm{N}_{2} \mathrm{O}_{(\mathrm{g})}\right)$ emissions comprised up to $10 \%$ of the removed influent nitrogen, but emissions disappeared after proliferation of AnaerAOB. Microbial communities were radially stratified, with aerobic ammonium-oxidizing bacteria (AerAOB) colonizing nearest to and AnaerAOB furthest from the membrane. Despite the presence of nitrite-oxidizing bacteria, this work demonstrated that these autotrophic processes can be successfully coupled in an MABR with continuous aeration, achieving the benefits of competitive specific $\mathrm{N}$ removal rates and the elimination of gaseous nitrogen oxide emissions.
\end{abstract}

Key words: ammonium-oxidizing bacteria; anammox; FISH; hollow fiber; membrane aerated biofilm reactor; nitritation; nitrite oxidizing bacteria; nitrous oxide

\section{Introduction}

$\mathrm{C}$ OMPARED WITH CONVENTIONAL nitrification and denitrification, partial nitrification to nitrite $\left(\mathrm{NH}_{3}\right.$ to $\mathrm{NO}_{2}^{-}$, nitritation) and subsequent anaerobic ammonium oxidation $\left(\mathrm{NH}_{3}+\mathrm{NO}_{2}^{-}\right.$to $\mathrm{N}_{2}$ and $\mathrm{NO}_{3}^{-}$, anammox) requires fewer external inputs and produces less biomass. While strategies exist to wash out undesirable nitrite-oxidizing bacteria (NOB) from such autotrophic systems in suspended growth (Hellinga et al., 1998; Fux et al., 2002; Hao et al., 2002; Blackburne et al., 2008), the use of washout to control NOB is not feasible with fixed-film processes due to the high solid retention time.

${ }^{*}$ Corresponding author: Department of Civil and Environmental Engineering, 309 Dana Engineering Bldg., Bucknell University, One Dent Drive, Lewisburg, PA 17837. Phone: 570-577-1615; Fax: 570577-3415; E-mail: kevin.gilmore@bucknell.edu

Present affiliations: 'Department of Civil and Environmental Engineering, Bucknell University, Lewisburg, Pennsylvania; "Tokyo University of Agriculture and Technology, Tokyo, Japan; "Microbiological and Chemical Exposure Assessment Research Division, Office of Research and Development, National Exposure Research Laboratory, U.S. Environmental Protection Agency, Cincinatti, Ohio.
Alternatively, nitrite oxidation can be minimized in conventional co-diffusion biofilms by establishing low dissolved oxygen (DO) and/or elevated temperature conditions (Picioreanu et al., 1997; Helmer et al., 2001; Pynaert et al., 2004; Furukawa et al., 2006). Unfortunately, because co-diffusion biofilms provide the electron donor and acceptor from the same phase (liquid), it can be difficult to completely decouple the loadings of these two substrates, thus limiting optimization of oxygen transfer efficiency and overall $\mathrm{N}$ removal.

Membrane-aerated biofilm reactors (MABRs) offer counterdiffusion delivery of electron donor and acceptor, allowing independent control of each as well as a high transfer efficiency, high substrate utilization rates, reduced volatile organic compound emission due to bubbleless oxygenation, and redox stratification of the biofilm (Ahmed and Semmens, 1992; Brindle and Stephenson, 1996; Schramm et al., 2000; Terada et al., 2003, 2007; Cole et al., 2004). MABRs have been successfully applied for treatment of carbonaceous wastewaters (Cole et al., 2004; LaPara et al., 2006), nitrification (Hibiya et al., 2000; Terada et al., 2006), and total nitrogen removal (Hibiya et al., 2003; Terada et al., 2003; Pellicer-Nacher et al., 2010). Stable nitritation has been established in continuously aerated MABRs for short durations (<60 days; Terada et al., 2004; Downing and Nerenberg, 2008). Nitritation and 
anaerobic ammonium oxidation have also been coupled in a completely autotrophic MABR by artificially distributing the inoculum biomass using an external biofilm support skeleton (Gong et al., 2007, 2008). Approaches proposed for controlling $\mathrm{NOB}$ in counter-diffusion MABRs include controlling the oxygen to ammonium flux ratio (Bernet et al., 2005; Terada et al., 2007; Lackner et al., 2008) and the DO concentration at the membrane-biofilm interface (Downing and Nerenberg, 2008). Recently, successful autotrophic $N$ removal efficiencies up to $72 \%$ were obtained in an intermittently aerated MABR, leading to repression of NOB and emergence of AnaerAOB (Pellicer-Nacher et al., 2010), although NOB were not completely eliminated. However, to date, no reports exist on the stable and long-term coexistence of these two metabolic groups of AerAOB and AnaerAOB in biofilms grown de novo in continuously aerated MABRs.

A consequence of low DO concentrations in $\mathrm{N}$ removal processes is autotrophic denitrification of nitrite $\left(\mathrm{NO}_{2}^{-}\right)$to nitric oxide $\left(\mathrm{NO}_{(\mathrm{g})}\right)$ and nitrous oxide $\left(\mathrm{N}_{2} \mathrm{O}_{(\mathrm{g})}\right)$ by AerAOB with ammonium as the electron donor (Poth and Focht, 1985; Kester et al., 1997; Schmidt and Bock, 1997, 1998). Genome sequencing of several AerAOB has confirmed the presence of nitrite reductase (nir) and nitric oxide reductase (nor) genes (Chain et al., 2003; Stein et al., 2007), but not of a nitrous oxide reductase (nos) gene. Formation of these detrimental gases also occurs via reduction of $\mathrm{NO}_{2}^{-}$and $\mathrm{NO}_{3}^{-}$during heterotrophic denitrification (Kester et al., 1997; Tallec et al., 2006). In systems where nitritation and anammox are coupled, there is the potential for AnaerAOB to compete with AerAOB for nitrite, thus limiting the AerAOB ability to denitrify to $\mathrm{NO}_{(\mathrm{g})}$ and $\mathrm{N}_{2} \mathrm{O}_{(\mathrm{g})}$. Coupling these two metabolisms in one reactor may, hence, reduce $\mathrm{N}_{2} \mathrm{O}_{(\mathrm{g})}$ emissions, though this has only recently been investigated in MABRs.

The present study examined the capability of a continuously aerated MABR to achieve stable nitritation coupled with anaerobic ammonium oxidation while treating a synthetic high-strength nitrogenous wastewater. Performance was related to oxygen and ammonium loadings at a low membranebiofilm interface DO concentration $(<1.0 \mathrm{mg} / \mathrm{L})$ to achieve desired metabolic outcomes. Nitrogen mass balances were performed to examine the fate of influent nitrogen, and the production of gaseous oxides of nitrogen is quantified. Finally, spatial distribution of AerAOB, NOB, and AnaerAOB microbial populations was examined.

\section{Methods}

\section{Reactor configuration}

The MABR was modeled after Rector et al. (2004) without rotation of the membrane module (Supplementary Fig. S1 and Supplementary Table S1). The 98 fibers were Silastic polydimethylsiloxane laboratory tubing (Dow Corning 508-009), $3.18 \mathrm{~mm}$ outer diameter, $1.98 \mathrm{~mm}$ inner diameter, potted in chlorinated polyvinyl chloride end caps, and were operated in an open-ended, flow-through configuration. The specific membrane (outer) surface area was $0.715 \mathrm{~cm}^{2} / \mathrm{cm}^{3}$ of reactor vessel volume. The vertical reactor was $9.4 \mathrm{~cm}$ diameter and $63 \mathrm{~cm}$ in height. Temperature was controlled at $30^{\circ} \mathrm{C}$. Liquid flow was recycled at a constant rate equivalent to 200 reactor volumes per day to minimize boundary layer resistance. Inlet aeration gas (either air or $80 \%$ argon $/ 20 \%$ oxygen) was controlled at $0.013 \mathrm{~m}^{3}$ per day by a mass flow controller (Aalborg
GFC-17). Lumen pressure was maintained by a backpressure needle valve. Bulk liquid DO was monitored by an Orion Model 97-08 oxygen electrode (Thermo Fisher Scientific) inserted into a flow cell. $\mathrm{pH}$ was automatically controlled with sodium carbonate to typically between 7.0 and 7.6. Additional details regarding the reactor are described in the Supplementary Data and elsewhere (Gilmore et al., 2009).

\section{Biomass}

The reactor was inoculated only once, at startup, with $1 \mathrm{~g}$ of biomass from two sources: (1) $0.66 \mathrm{~g}$ from a nitrifying activated sludge acclimated to intermittent aeration for 9 days at $30^{\circ} \mathrm{C}$ and (2) $0.34 \mathrm{~g}$ from a mixture of two seed sludge sources taken from a lab-scale bioreactor performing oxygen-limited autotrophic nitrification and denitrification (OLAND; Courtesy of W. Verstraete, Ghent, Belgium) and a full-scale plant achieving anaerobic ammonium oxidation (Courtesy of B. Wett, Strass, Austria).

\section{Reactor operation}

The MABR was operated for 555 days treating an organic carbon-free synthetic wastewater designed to mimic the nitrogenous component resulting from source separation or a confined human operation such as a long-term space exploration mission: $47.1 \mathrm{mM} \mathrm{NH}_{3}-\mathrm{N}$ (added as $\mathrm{NH}_{4} \mathrm{HCO}_{3}$ ), $14.3 \mathrm{mM} \mathrm{NaCl}$,

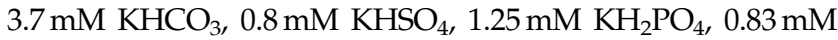
$\mathrm{MgSO}_{4}, 1.23 \mathrm{mM} \mathrm{CaCl}_{2}$, and $0.11 \mathrm{mM} \mathrm{FeCl}_{2}$, in distilled water (Smith et al., 2008).* To investigate the hypothesis that a completely autotrophic system could be developed in this configuration, organic carbon was not included in the feed, which is an approach used by others (Smith et al., 2008). This also facilitated as detailed nitrogen balancing as possible with minimal contribution of heterotrophic organisms. Average substrate loadings for each phase of operation are described in Table 1.

\section{Calculation of loading rates and fluxes of oxygen and nitrogen}

The oxygen surface loading was defined as the maximum potential flux of oxygen across the membrane into the biofilm using a biofilm base DO concentration of $0 \mathrm{mg} / \mathrm{L}\left(L_{\mathrm{O} 2}=K\left[C^{*}\right]\right.$; Pellicer-Nacher et al., 2010). The mass transfer coefficient was $9.17 \times 10^{-4} \mathrm{~cm} / \mathrm{s}$ and was independent of lumen pressure and velocity in the range of lumen pressures relevant to the present work (Gilmore et al., 2009). The gas phase oxygen concentration $(y)$ was shown by outlet gas measurements and by a mechanistic oxygen transfer model to be nonuniform along the length of the fiber, with the outlet oxygen concentration equal to $\sim 45 \%$ of the inlet gas concentration (Gilmore et al., 2009). Therefore, a linear average concentration was used in the oxygen surface load calculation $\left[y_{\text {inlet }}+\left(0.45 \times y_{\text {inlet }}\right)\right] / 2$. The nitrogen surface loading $\left(L_{\mathrm{NH} 4}\right)$ was based on inlet mass flow rate divided by the membrane outer surface area.

\section{Nitrogen mass balancing and metabolic pathway determination}

Mass balance equations and reaction stoichiometry were used to determine the fate of nitrogen and oxygen utilized by

*Hummerick, M. (2005). Personal communication. Dynamac Corp., Kennedy Space Center, FL. 
Table 1. Surface load Ratio of Oxygen and Nitrogen for Selected Operating Periods

\begin{tabular}{|c|c|c|c|c|c|}
\hline Phase of operation & $\begin{array}{l}\text { Lumen } \\
\text { gas }^{\mathrm{a}}\end{array}$ & $\begin{array}{c}\text { Lumen pressure, } \\
k P a \text { (psig) }\end{array}$ & $\begin{array}{c}\text { Max. } \mathrm{O}_{2} \text { surface } \\
\text { load, } g \mathrm{O}_{2} / m^{2} \text { daily }\end{array}$ & $\begin{array}{c}\text { Applied } \mathrm{NH}_{4}^{+} \\
\text {load, } g \mathrm{~N} / \mathrm{m}^{2} \text { daily }\end{array}$ & $\begin{array}{l}\text { Load ratio, } \\
\qquad \mathrm{O}_{2}: \mathrm{N}\end{array}$ \\
\hline II, days 24-92 & Air & $54.3(8)$ & 6.16 & 1.57 & 3.94 \\
\hline IIIa, days 93-108 & Air & $33.9(5)$ & 5.35 & 1.63 & 3.29 \\
\hline IIIb, days 109-152 & Air & $34.6(5)$ & 5.35 & 2.35 & 2.28 \\
\hline IIIc, days 153-297 & Argon: $\mathrm{O}_{2}$ & $34.8(5)$ & 5.16 & 2.32 & 2.22 \\
\hline IV, days 298-550 & Argon: $\mathrm{O}_{2}$ & $27.8(4)$ & 4.90 & 2.25 & 2.18 \\
\hline
\end{tabular}

${ }^{\mathrm{a} A r g o n} \mathrm{O}_{2}=80 \%$ argon, $20 \% \mathrm{O}_{2}$.

${ }^{\mathrm{b}}$ Oxygen surface load calculated as maximum imposed oxygen flux across membrane into biofilm, $L_{\mathrm{O} 2(\max )}=K\left(C^{*}-C_{\text {biofilm base }}\right)$, where $C_{\text {biofilm base }}=0 \mathrm{mg} / \mathrm{L}$ and $K=9.17 \times 10^{-4} \mathrm{~cm} / \mathrm{s}$ (Gilmore et al., 2009), and gas-phase oxygen concentration was the average of inlet and outlet concentrations.

${ }^{c} L_{\mathrm{NH} 4+}$ is based on ammonium-N loaded to the reactor.

AerAOB, NOB, and AnaerAOB. Two possible conditions were evaluated: Condition 1 assumed that all oxygen goes to either ammonium oxidation by AerAOB or nitrite oxidation by $\mathrm{NOB}$, and excess $\mathrm{NO}_{3}^{-}$is generated for denitrification by heterotrophs; Condition 2 assumed that heterotrophic denitrification is negligible and excess oxygen goes to aerobic heterotrophs utilizing decay products from AerAOB and NOB. Details for these calculations can be found in the Supplementary Data (Section 2).

\section{Biofilm sectioning for fluorescence in situ hybridization}

MABR biofilm was fixed in situ (in the reactor vessel while still attached to the membranes) for analysis by fluorescence in situ hybridization (FISH). Additional details regarding the fixation, cryosectioning, hybridizations, and imaging of biofilm sections for thickness measurements and FISH are provided in the Supplementary Data (Section 3).

\section{Oxygen microsensor measurements}

Oxygen profiles were performed on days 204 and 458 using an OX-10 Clark-type oxygen microsensor (Unisense) with a specified nominal tip diameter between 8 and $12 \mu \mathrm{m}$. Calibrations and profiling were performed as described elsewhere (Gilmore et al., 2009).

\section{Analytical methods}

Duplicate or triplicate samples for soluble analyses were filtered through $0.45 \mu \mathrm{m}$ nitrocellulose membrane filters. As available, all analyses were performed in accordance with procedures outlined in Standard Methods for the Examination of Water and Wastewater (APHA et al., 1998). Analytical methods for nitrogen species are described in the Supplementary Data (Section 4).

\section{Results and Discussion}

Controlling loading rates of oxygen and nitrogen allows control of NOB long enough to establish an active AnaerAOB population

Performance was categorized into four phases as described below and shown in Fig. 1 and Table 1.

Phase I, days 0-23, startup. Establishment of nitritation during Phase I at $0.83 \mathrm{~g} \mathrm{NH}_{4}^{+}-\mathrm{N} / \mathrm{m}^{2}$ daily (normalized to outer membrane area) was rapid, as observed by others (Hibiya et al., 2003; Kindaichi et al., 2006). After the initial ammonium was consumed by day 20, lumen pressure was decreased from $\sim 70 \mathrm{kPa}(10 \mathrm{psig})$ to $55 \mathrm{kPa}(8 \mathrm{psig})$ and the influent load doubled, after which ammonium was never limiting again during the experiment (lowest measured effluent concentration was $6 \mathrm{mg} / \mathrm{L}$ as $\mathrm{N}$ ).

Phase II, days 24-92, nitritation. Predominantly, nitritation was achieved from days 24-70 at a loading of $1.57 \mathrm{~g}$ $\mathrm{NH}_{4}^{+}-\mathrm{N} / \mathrm{m}^{2}$ per day. The estimated $L_{\mathrm{O} 2} / L_{\mathrm{NH} 4}$ ratio (Table 1 ) exceeded the amount required for complete nitritation (3.43). Nonetheless, NOB activity was not observed for most of this phase. The complete oxidation of ammonium, plus the predominance of nitrite relative to nitrate, was evidence of nitritation as the dominant metabolism. After day 70, however, a drop in effluent $\mathrm{NO}_{2}^{-}$and increase in effluent $\mathrm{NO}_{3}^{-}$suggested proliferation of NOB, similar to prior studies (Sliekers et al., 2005; Terada et al., 2006). Previous work has suggested several control approaches for minimizing such NOB activity in MABRs: (1) use of an inoculum acclimated to low DO in

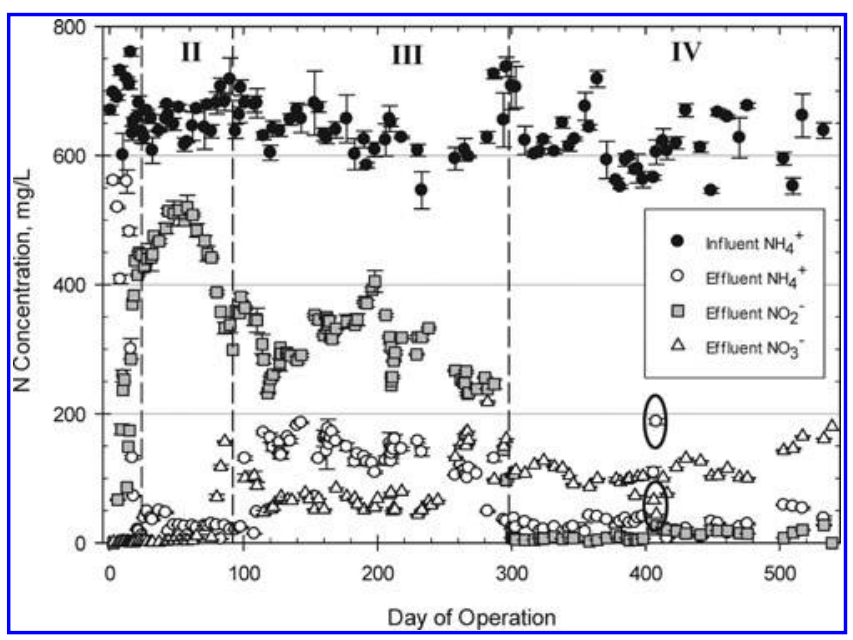

FIG. 1. Reactor performance. Soluble nitrogen species in reactor effluent over the duration of operation. Nitrogen in the feed was composed entirely of ammonium. Roman numerals correspond to phases of operation. Data points circled reflect $\mathrm{NH}_{4}^{+}$accumulation and $\mathrm{NO}_{3}^{-}$reduction due to transient loss of aeration on day 405 . 
order to select for AerAOB with low $K_{\mathrm{O} 2}$ values (Terada et al., 2007), (2) precise control of the oxygen/ammonium flux ratio (Terada et al., 2007), or (3) sequential aeration (Pellicer-Nacher et al., 2010). Because the use of an acclimated seed did not prevent the appearance of NOB here, this provides further evidence that low-DO, elevated-temperature seed sludge acclimation alone is not sufficient to exclude NOB. Therefore, control of the oxygen/ammonium surface load ratio was used to attempt to control the NOB proliferation.

Phase III, days 93-297, nitritation and partial nitrite oxidation. On day 92 , lumen pressure was reduced to $34 \mathrm{kPa}(5$ psig), resulting in rapid stabilization of effluent oxidized nitrogen. On day 108, a load increase to $2.35 \mathrm{~g} \mathrm{NH}_{4}^{+}-\mathrm{N} / \mathrm{m}^{2}$ daily resulted in a decrease in estimated $\mathrm{O}_{2}: \mathrm{N}$ load ratio $\left(\mathrm{L}_{\mathrm{O} 2} / \mathrm{L}_{\mathrm{NH} 4+}\right)$ to 2.28. As a result, oxygen-limiting conditions were established, and residual $\mathrm{NH}_{4}^{+}$stabilized at concentrations $\sim 20 \%$ of the influent load. The presence of both nitrite and nitrate for the remainder of this phase indicated that a combination of nitritation with partial nitrite oxidation to nitrate occurred. Based on $\mathrm{pH}$ and nitrogen speciation, neither free ammonia $(1.6 \mathrm{mg} / \mathrm{L}$ N) nor free nitrous acid (negligible) was likely to have inhibited NOB (Anthonisen et al., 1976; Kim et al., 2006; Vadivelu et al., $2006,2007)$. Therefore, the elevated temperature, control of the relative surface loading of oxygen/ammonium presumably, and perhaps low membrane-biofilm interface DO (Supplementary Data, Section 6) allowed nitritation to predominate, despite the presence of NOB under continuous aeration.

Phase IV, days 298-550, nitritation + anaerobic ammonium oxidation. Between days 287 and 298, concentrations of $\mathrm{NH}_{4}^{+}$and $\mathrm{NO}_{2}^{-}$decreased drastically to $<30 \mathrm{mg} / \mathrm{L}$ and $<10 \mathrm{mg} / \mathrm{L}$, respectively, with no preceding change in ammonium or oxygen loading. The lumen pressure was decreased to $27.6 \mathrm{kPa}$ (4 psig) on day 298 to further lower $L_{\mathrm{O} 2} / L_{\mathrm{NH} 4+}$ to 2.18. An anaerobic perturbation on day 405 due to an empty aeration gas tank resulted in transient $\mathrm{NH}_{4}^{+}$accumulation and a drop in $\mathrm{NO}_{3}^{-}$, the latter of which indicated the presence of heterotrophic denitrifiers (data circled in Fig. 1 and visible as spike at day 405 in Fig. 2). After the tank was replaced, performance was rapidly restored and stabilized. During Phase IV, the reactor achieved a specific $\mathrm{N}$ removal rate of $1.7 \mathrm{~g} \mathrm{~N} / \mathrm{m}^{2}$ per day, or $75 \%$ of the influent $\mathrm{N}$ load ( $2.25 \mathrm{~g} \mathrm{~N} / \mathrm{m}^{2}$ per day). Normalized to reactor volume, nitrogen removal was equivalent to $0.14 \mathrm{~kg} \mathrm{~N} / \mathrm{m}^{3}$ daily.

The ratio of oxygen flux to ammonium flux into the biofilm has been shown through modeling and experimental studies to be a potential control parameter for achieving partial nitritation (Bernet et al., 2005; Matsumoto et al., 2007; Terada et al., 2007). However, substrate fluxes themselves are not directly controllable but rather they are a function of mass loads, reactor hydrodynamics, and especially biokinetics. In contrast, recent work (Pellicer-Nacher et al., 2010) has shown that the ratio of oxygen surface loading relative to ammonium surface loading can be an effective practical parameter for controlling MABR performance. Table 1 shows that this substrate loading ratio tracks well with performance during the discrete phases of operation. While the Phase IV $L_{\mathrm{O} 2} /$ $L_{\mathrm{NH} 4}+$ was greater than theoretical reaction stoichiometries proposed by others of $1.75 \mathrm{~g} \mathrm{O}_{2} / \mathrm{g} \mathrm{NH}_{4}^{+}-\mathrm{N}$ (Terada et al., 2007) or $1.96 \mathrm{~g} \mathrm{O}_{2} / \mathrm{g} \mathrm{NH}_{4}^{+}-\mathrm{N}$ (assuming $57 \%$ of influent $\mathrm{NH}_{4}^{+}$is oxidized by AerAOB to achieve the 1.32:1 $\mathrm{NO}_{2}^{-}: \mathrm{NH}_{4}^{+}$ratio for AnaerAOB; Sliekers et al., 2002), reactor performance indicated that the Phase IV $L_{\mathrm{O} 2} / L_{\mathrm{NH} 4}+$ was suitable for the biofilm to support AnaerAOB activity. Therefore, the results further support the use of relative surface load control for establishing coupled nitritation and anammox.

A mass balance of $\mathrm{N}$ species was performed during Phase IV to corroborate the apparent achievement of nitritation coupled with anaerobic ammonium oxidation (Supplementary Data, Section 2). The contribution of heterotrophic denitrifiers could not be determined; however, it was calculated that between $82 \%$ and $85 \%$ of the influent nitrogen proceeded through anaerobic ammonium oxidation (defined as $\mathrm{NH}_{4}^{+}$ oxidized by AnaerAOB $+\mathrm{NO}_{2}^{-}$reduced by AnaerAOB). With heterotrophic denitrification neglected, as little as $14 \%$ of the $\mathrm{NO}_{2}^{-}$produced by AerAOB was oxidized by NOB. Hence, the predominant metabolisms in the reactor at this time were aerobic nitritation and anaerobic ammonium oxidation.

Prior work (Pellicer-Nacher et al., 2010) has shown slightly lower $\mathrm{NOB}$ activity in an MABR with sequential aeration $\left(\Delta \mathrm{NO}_{2}^{-} \mathrm{NOB} / \Delta \mathrm{NO}_{2}^{-}=\sim 9 \%\right)$. While the difference in the two studies ( $9 \%$ vs. $14 \%-19 \%$ ) cannot be concluded as statistically significant, the present system may not provide the biofilm base with sufficiently low oxygen tension to control NOB proliferation when compared to the sequential aeration approach. The

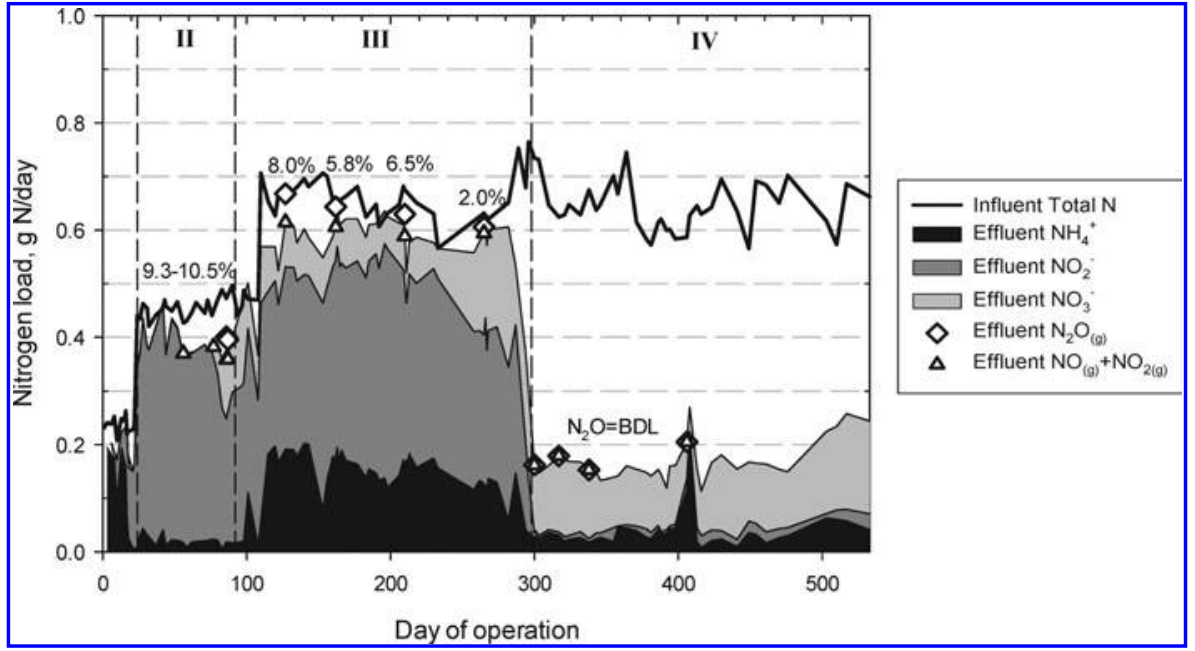

FIG. 2. Aqueous and gaseous effluent nitrogen speciation (cumulative) from $\mathrm{N}$ balances. Influent contained only $\mathrm{NH}_{4}^{+}$. All effluent species are cumulative. Gaseous species are marked with $(\mathrm{g})$. BDL, below detection limit of $100 \mathrm{ppm}_{\mathrm{v}}$. 
specific nitrogen removal rate normalized to reactor volume $\left(0.14 \mathrm{~kg} \mathrm{~N} / \mathrm{m}^{3}\right.$ daily) is up to one order of magnitude lower than in other studies (Strous et al., 1997; Sliekers et al., 2003; Pynaert et al., 2004). The reason for this is due to the low packing density of membranes relative to reactor volume, as well as potential mass transfer limitation in the inner regions of the fiber bundle. Improvements in both characteristics would result in higher removal rates per unit volume of reactor system.

\section{Coupling anaerobic ammonium oxidation with low-DO nitritation eliminates $\mathrm{N}$-oxide emissions}

Figure 2 illustrates cumulative effluent nitrogen speciation (excluding $\mathrm{N}_{2 \text { (gas) }}$ ) relative to the influent $\mathrm{N}$ loading. Biomass $\mathrm{N}$ was calculated to be negligible $(<1 \%$ of the daily total influent N). Early in the study, $\mathrm{NO}_{x(\mathrm{~g})}$ and $\mathrm{N}_{2} \mathrm{O}_{(\mathrm{g})}$ contribution to the $\mathrm{N}$ balances was significant, however, with $\mathrm{NO}_{x(\mathrm{~g})}$ and $\mathrm{N}_{2} \mathrm{O}_{(\mathrm{g})}$ concentrations averaging $56 \operatorname{ppm}_{\mathrm{v}}(n=5)$ and 2,540 $\operatorname{ppm}_{\mathrm{v}}(n=6)$, respectively. Short-term operational changes did not result in emission reductions that could be attributed to biological mechanisms (Supplementary Data, Section 5).

The shift toward anaerobic ammonium oxidation was accompanied by a remarkable decrease in gaseous emissions (Fig. 2). $\mathrm{NO}_{(\mathrm{g})}$ and $\mathrm{NO}_{2(\mathrm{~g})}$ fell to below $7 \mathrm{ppm}_{\mathrm{v}}$ each following day 300 , and $\mathrm{N}_{2} \mathrm{O}_{(\mathrm{g})}$ fell below the detection limit of 100 ppm $_{\mathrm{v}}$. Thus, when AnaerAOB activity was established in the system, $\mathrm{N}$-oxide emissions were essentially eliminated.

It is likely that the $\mathrm{NO}_{(\mathrm{g})}$ and $\mathrm{N}_{2} \mathrm{O}_{(\mathrm{g})}$ in this study were attributable to nitrite reduction by AerAOB. Emissions were present only in the first 300 days of the study and highest at day 127, when AerAOB dominated the reactor. Further, high $\mathrm{NO}_{2}^{-}$concentrations such as those observed here have been shown to cause reduction of $\mathrm{NO}_{2}^{-}$by AerAOB (Payne et al., 1971; Averill, 1996; Stein and Yung, 2003; Beaumont et al., 2004). While this disappearance of emissions has been shown in an MABR with sequential aeration (PellicerNacher et al., 2010), we demonstrate here for the first time that this benefit is also realized under continuously aerated conditions.

DO microsensor profiles on day 204 (Gilmore et al., 2009) and day 458 (Supplementary Data, Section 6) revealed a microaerobic region extending at most $90 \mu \mathrm{m}$ from the membrane, with membrane surface DO concentrations ranging from $0.80 \mathrm{mg} / \mathrm{L}$ at Port 1 to $0.20-0.40 \mathrm{mg} / \mathrm{L}$ at Ports $2-4$. This limited oxygen penetration into the biofilm was lower than comparable studies with continuous aeration (Schramm et al., 2000; Terada et al., 2003). The low DO concentrations $(<1.0 \mathrm{mg} / \mathrm{L})$ measured at the base of the biofilm in this study are near the oxygen half-saturation coefficient values reported for AerAOB and NOB, and may have contributed to the successful outcompetition of NOB by AerAOB. Other studies (Fux et al., 2004; Downing and Nerenberg, 2008) have also found that lowering DO generally favored AerAOB over NOB.

\section{Low-DO microenvironments generate radial stratification of microbial communities in the biofilm}

Interrogation of the microbial community in the radial direction revealed clear patterns. AerAOB predominated near the membrane, either in microcolonies or in striated bands (NEU; Fig. 3A, B). These near-membrane AerAOB were dominated by the halophilic and halotolerant Nitrosomonas europaea/Nitrosomonas eutropha lineage as evidenced by hybridization with NEU (Fig. 3B). In some biofilm sections, a second group of AerAOB was observed further from the membrane (Fig. 3C, cyan), which hybridized with Nmo218/ Cluster 6a192 probe mixture, indicating homology with the Nitrosomonas oligotropha lineage. Nitrosospira sp. (probe Nsv443) was not detected. Data on the concentration of ammonium within the biofilm were not collected (i.e., via microsensors). However, throughout the study, bulk liquid ammonium concentrations exceeded reported $K_{\mathrm{NH} 4}$ values for the AerAOB studied here (Martens-Habbena et al., 2009), a condition that may have provided the halophilic and halotolerant Nitrosomonas spp. with an advantage.

As suggested by reactor performance, NOB were detected and were most often of the Nitrospira lineage, and Nitrobacterlike NOB were sparsely detected in some samples (signals with NIT3). Nitrospira microcolonies were located near the membrane (Nspra662; Fig. 3G, cyan) and were often in close proximity to microcolonies of AerAOB (Nso190; Fig. 3H, magenta), although some differences were observed based on axial sample location.

Prior work has demonstrated that the composition of the biomass inoculum is significant in determining the ultimate microbial community (Terada et al., 2010). If r-strategist Aer$\mathrm{AOB}$ were present in the inoculum, they colonized the membrane surface rapidly, deprived NOB of oxygen, and reduced the incidence of r-strategist $\mathrm{NOB}$, such as Nitrobacter. In the MABR studied here, r-strategists dominated the AerAOB population, likely preventing prospective Nitrobacter from colonizing. However, a high-rate NOB community in the MABR was also suppressed by the low DO concentration at the membrane-biofilm interface $(<1.0 \mathrm{mg} / \mathrm{L})$, which favored $\mathrm{K}$ strategist NOB Nitrospira over r-strategist Nitrobacter. Although work is needed to reproduce this outcome, early colonization by an r-strategist AerAOB and a low-DO biofilm base concentration may have contributed to a biofilm displaying good nitritation ultimately suitable for colonization by AnaerAOB.

Near the bulk liquid side of the biofilm, positive signals for Planctomycetales (Pla46; Fig. 3D, magenta) were examined with more specific probes for AnaerAOB groups: Amx820 and Kst157. A band of AnaerAOB clusters (Amx820; Fig. 3E, $\mathrm{F}$, blue) was visible in the outer region of the biofilm near the anaerobic bulk liquid, while no substantial signal from Kst157 was observed (Fig. 3E, F, magenta). Thus, Brocadiaanammoxidans was the predominant AnaerAOB lineage present.

In contrast to MABR with sequential aeration (PellicerNacher et al., 2010), in the MABR reported here, AnaerAOB were not as directly collocated with AerAOB, because continuous aeration did not provide anoxic time periods needed for AnaerAOB to grow near AerAOB. Instead, radial stratification of microbial populations across the biofilm was consistent with previous experimental and modeling studies (Terada et al., 2003; Lackner et al., 2008; Smith et al., 2008). In addition, the presence of heterotrophs was predicted by mass balances and performance (see previous Phase IV discussion and Supplementary Data, Section 2). It is possible that the regions of FISH micrographs containing nontarget organisms (differences between areas fluorescing green in Fig. 3G and no signal in Fig. $3 \mathrm{H}$ ) may have contained heterotrophs, nontarget AerAOB and AnaerAOB, and ammonia-oxidizing archaea, or other communities. Prior computational modeling 

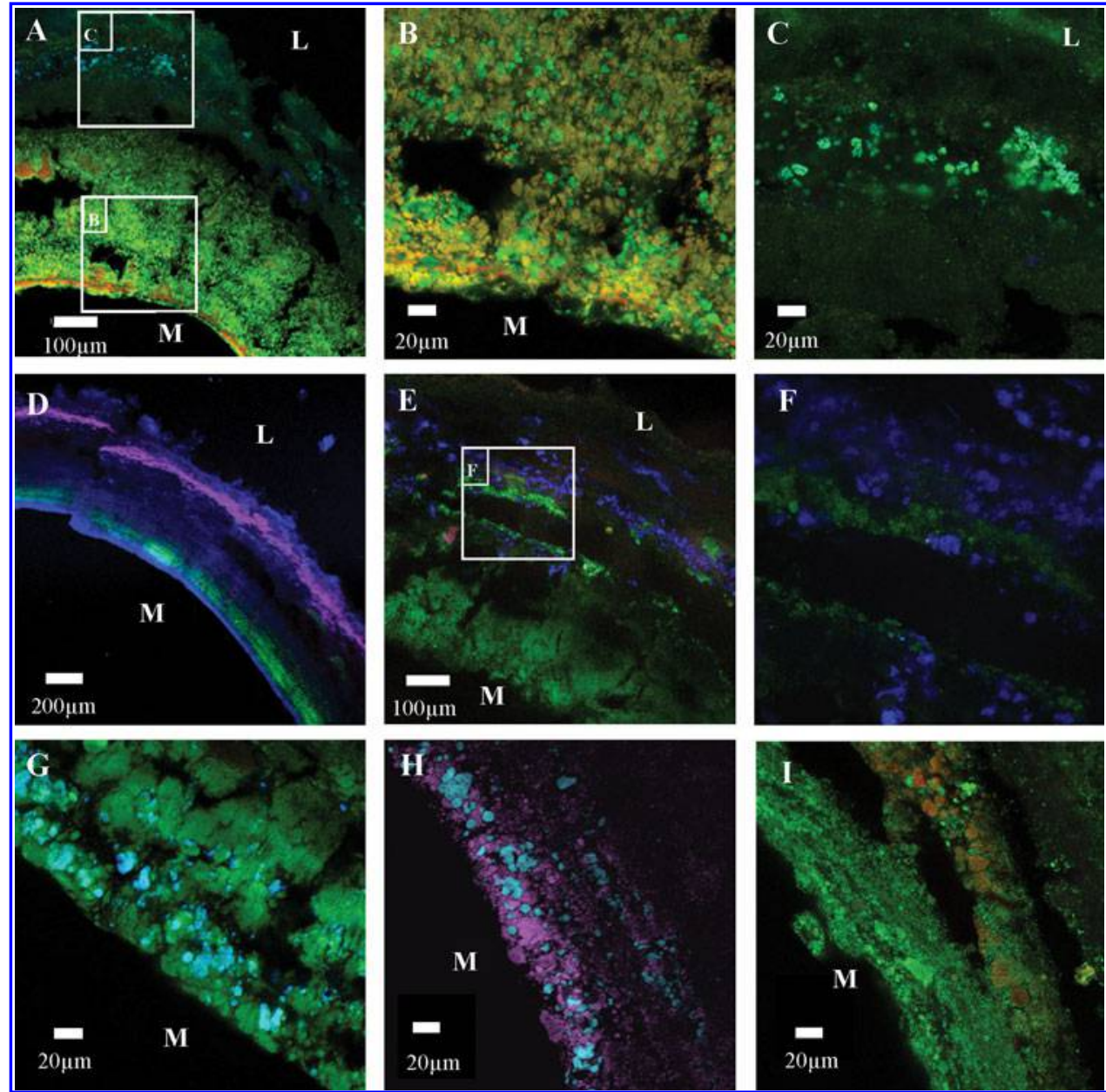

has predicted, between AerAOB and AnaerAOB layers, a middle region of heterotrophs feeding on biomass decay products (Lackner et al., 2008), although the identity of these nontarget communities could not be verified in the present study. This observation underscores the need to incorporate heterotrophic metabolisms in MABR models, even when considering predominantly nitrogenous wastewaters. As illustrated in the nitrogen balances, the contribution of heterotrophs to oxygen consumption and/or heterotrophic denitrification may be significant relative to the autotrophic communities present. The presence of AerAOB and NOB at significant distances from the membrane (Fig. 3A, C) was unexpected, as DO would be negligible in this region. The mechanisms that determine temporal changes in community locations are not clear, and further study could consider community analysis at different times over the life of the system to determine the nature of these dynamics.

\section{Summary}

This study demonstrates that a biofilm grown de novo with continuous aeration can couple nitritation and anaerobic ammonium oxidation in a single MABR. Sustained nitrogen removal from a synthetic wastewater free of organic carbon was achieved for an extended duration, using relative loading ratios of oxygen to nitrogen as the primary control parameter for outcompeting NOB. Removal rates of $1.7 \mathrm{~g} \mathrm{~N} / \mathrm{m}^{2}$ daily membrane area $\left(0.14 \mathrm{~kg} \mathrm{~N} / \mathrm{m}^{3}\right.$ daily reactor volume) were
FIG. 3. Micrographs of biofilm sections at the end of operation, subjected to different $16 \mathrm{~S}$ rRNA-targeted fluorescent probe combinations. (A-C) Green, all bacteria (EUBmix); yellow/orange, $N$. europaea and N. eutropha (NEU); cyan, N. oligotropha (Nmo218 + Cluster 6a192). (D) Blue, all DNA (DAPI); green, AerAOB (Nso1225); magenta, Planctomycetales (Pla46). (E, F) Green, AerAOB (Nso190+Nmo218+Cluster 6a192); blue, Ca. Brocadia + Ca. Kuenenia (Amx820); magenta, Ca. Kuenenia only (KST157).

(G-I) Green, all bacteria (EUBmix); cyan, Nitrospira (Ntspa662); magenta $\mathbf{( H}$ only), AerAOB (Nso190); orangelyellow, Nitrobacter (NIT3). Scales as shown. M, membrane side of biofilm; L, bulk liquid side of biofilm. achieved, with up to $85 \%$ of the influent nitrogen proceeding through anaerobic ammonium oxidation. Because new wastewater solutions must be compatible with the greater goal of environmental sustainability, low-DO nitritation systems must mitigate the release of the greenhouse gas nitrous oxide. This work demonstrated that an important benefit of coupling these two autotrophic metabolisms in a single reactor is a disappearance of nitrogen oxide emissions.

\section{Acknowledgments}

Funding was provided by the National Aeronautics and Space Administration (NASA) grant to B.F.S. and N.G.L., and by a Danish Research Council grant to B.F.S.

\section{Author Disclosure Statement}

No competing financial interests exist.

\section{References}

Ahmed, T., and Semmens, M.J. (1992). Use of sealed end hollow fibers for bubbleless membrane aeration: experimental studies. J. Membr. Sci. 69, 1.

Anthonisen, A.C., Loehr, R.C., Prakasam, T.B.S., and Srinatu, E.G. (1976). Inhibition of nitrification by ammonia and nitrous acid. I. Wat. Pollut. Control Fed. 48, 835.

American Public Health Association (APHA), American Water Works Association (AWWA), and Water Environment 
Federation (WEF). (1998). Standard Methods for the Examination of Water and Wastewater. New York: APHA.

Averill, B.A. (1996). Dissimilatory nitrite and nitric oxide reductases. Chem. Rev. 96, 2951.

Beaumont, H.J.E., Lens, S.I., Reijnders, W.N.M., Westerhoff, H.V., and van Spanning, R.J.M. (2004). Expression of nitrite reductase in Nitrosomonaseuropaea involves NsrR, a novel nitrite-sensitive transcription repressor. Molec. Microbiol. $54,148$.

Bernet, N., Sanchez, O., Cesbron, D., Steyer, J.P., and Delgenès, J.P. (2005). Modeling and control of nitrite accumulation in a nitrifying biofilm reactor. Biochem. Eng. I. 24, 173.

Blackburne, R., Yuan, Z., and Keller, J. (2008). Partial nitrification to nitrite using low dissolved oxygen concentration as the main selection factor. Biodegradation 19, 303.

Brindle, K., and Stephenson, T. (1996). The application of membrane biological reactors for the treatment of wastewaters. Biotechnol. Bioeng. 49, 601.

Chain, P., Lamerdin, J., Larimer, F., Regala, W., Lao, V., Land, M., Hauser, L., Hooper, A., Klotz, M., Norton, J., SayavedraSoto, L., Arciero, D., Hommes, N., Whittaker, M., and Arp, D. (2003). Complete genome sequence of the ammonia-oxidizing bacterium and obligate chemolithoautotroph Nitrosomonas europaea. L. Bacteriol. 185, 2759.

Cole, A.C., Semmens, M.J., and LaPara, T.M. (2004). Stratification of activity and bacterial community structure in biofilms grown on membranes transferring oxygen. Appl. Environ. Microbiol. 70, 1982.

Downing, L.S., and Nerenberg, R. (2008). Effect of oxygen gradients on the activity and microbial community structure of a nitrifying, membrane-aerated biofilm. Biotechnol. Bioeng. 101, 1193.

Furukawa, K., Lieu, P.K., Tokitoh, H., and Fujii, T. (2006). Development of single-stage nitrogen removal using anammox and partial nitritation (SNAP) and its treatment performances. Water Sci. Technol. 53, 83.

Fux , Huang, D., Monti, A., and Siegrist, H. (2004). Difficulties in maintaining long-term partial nitritation of ammonium-rich sludge digester liquids in a moving-bed biofilm reactor (MBBR). Water Sci. Technol. 49, 53.

Fux, C.M., Boehler, M., Huber, P., Brunner, I., and Siegrist, H. (2002). Biological treatment of ammonium-rich wastewater by partial nitritation and subsequent anaerobic ammonium oxidation (anammox) in a pilot plant. L. Biotechnol. 99, 295.

Gilmore, K.R., Little, J.C., Smets, B.F., and Love, N.G. (2009). Oxygen transfer model for a flow-through hollow-fiber membrane biofilm reactor. L. Environ. Eng. 135, 806.

Gong, Z., Yang, F., Liu, S., Bao, H., Hu, S., and Furukawa, K. (2007). Feasibility of a membrane-aerated biofilm reactor to achieve single-stage autotrophic nitrogen removal based on anammox. Chemosphere, 69, 776.

Gong, Z., Liu, S., Yang, F., Bao, H., and Furukawa, K. (2008). Characterization of functional microbial community in a membrane-aerated biofilm reactor operated for completely autotrophic nitrogen removal. Biores. Technol. 99, 2749.

Hao, X., Heijnen, J.J., and van Loosdrecht, M.C.M. (2002). Sensitivity analysis of a biofilm model describing a one-stage completely autotrophic nitrogen removal (CANON) process. Biotechnol. Bioeng. 77, 266.

Hellinga, C., Shellen, A.A.J.C., Mulder, J.W., van Loosdrecht, M.C.M., and Heijnen, J.J. (1998). The SHARON process: An innovative method for nitrogen removal from ammonium-rich waste water. Water Sci. Technol. 37, 135.

Helmer, C., Tromm, C., Hippen, A., Rosenwinkel, K.-H., Seyfried, C.F., and Kunst., S. (2001). Single stage biological ni- trogen removal by nitritation and anaerobic ammonium oxidation in biofilm systems. Water Sci. Technol. 43, 311.

Hibiya, K., Terada, A., Tsuneda, S., and Hirata, A. (2003). Simultaneous nitrification and denitrification by controlling vertical and horizontal microenvironment in a membraneaerated biofilm reactor. J. Biotechnol. 100, 23.

Hibiya, K., Tsuneda, S., and Hirata, A. (2000). Formation and characteristics of nitrifying biofilm on a membrane modified with positively-charged polymer chains. Colloids Surfaces B Biointerfaces 18, 105.

Kester, R.A., Meijer, M.E., Libochant, J.A., De Boer, W., and Laanbroek, H.J. (1997). Contribution of nitrification and denitrification to the $\mathrm{NO}$ and $\mathrm{N}_{2} \mathrm{O}$ emissions of an acid forest soil, a river sediment and a fertilized grassland soil. Soil Biol. Biochem. 29, 1655.

Kim, D.-J., Lee, D.-I., and Keller, J. (2006). Effect of temperature and free ammonia on nitrification and nitrite accumulation in landfill leachate and analysis of its nitrifying bacterial community by FISH. Biores. Technol. 97, 459.

Kindaichi, T., Kawano, Y., Ito, T., Satoh, H., and Okabe, S. (2006). Population dynamics and in situ kinetics of nitrifying bacteria in autotrophic nitrifying biofilms as determined by real-time quantitative PCR. Biotechnol. Bioeng. 94, 1111.

Lackner, S., Terada, A., and Smets, B.F. (2008). Heterotrophic activity compromises autotrophic nitrogen removal in membrane-aerated biofilms: results of a modeling study. Water Res. 42, 1102.

LaPara, T.M., Cole, A.C., Shanahan, J.W., and Semmens, M.J. (2006). The effects of organic carbon, ammoniacal-nitrogen, and oxygen partial pressure on the stratification of membraneaerated biofilms. J. Ind. Microbiol. Biotechnol. 33, 315.

Martens-Habbena, W., Berube, P.M., Urakawa, H., de la Torre, J.R., and Stahl, D.A. (2009). Ammonia oxidation kinetics determine niche separation of nitrifying Archaea and Bacteria. Nature 461, 976.

Matsumoto, S., Terada, A., and Tsuneda, S. (2007). Modeling of membrane-aerated biofilm: Effects of $\mathrm{C} / \mathrm{N}$ ratio, biofilm thickness and surface loading of oxygen on feasibility of simultaneous nitrification and denitrification. Biochem. Eng. I. 37, 98.

Payne, W.J., Riley, P.S., and Cox, Jr., C.D. (1971). Separate nitrite, nitric oxide, and nitrous oxide reducing fractions from $\mathrm{Pseu}$ domonas perfectomarinus. L. Bacteriol. 106, 356.

Pellicer-Nacher, C., Sun, S.P., Lackner, S., Terada, A., Schreiber, F., Zhou, Q., and Smets, B.F. (2010). Sequential aeration of membrane aerated biofilm reactors for high-rate autotrophic nitrogen removal: experimental demonstration. Environ. Sci. Technol. 44, 7628.

Picioreanu, C., van Loosdrecht, M.C.M., and Heijnen, J.J. (1997). Modelling the effect of oxygen concentration on nitrite accumulation in a biofilm airlift suspension reactor. Water Sci. Technol. 36, 147.

Poth, M., and Focht, D.D. (1985). 15N Kinetic analysis of $\mathrm{N}_{2} \mathrm{O}$ production by Nitrosomonas europaea: An examination of nitrifier denitrification. Appl. Environ. Microbiol. 49, 1134.

Pynaert, K., Smets, B.F., Beheydt, D., and Verstraete, W. (2004). Start-up of autotrophic nitrogen removal reactors via sequential biocatalyst addition. Environ. Sci. Technol. 38, 1228.

Rector, T., Garland, J., Strayer, R.F., Levine, L., Roberts, M., and Hummerick, M. (2004). Design and Preliminary Evaluation of a Novel Gravity Independent Rotating Biological Membrane Reactor. Colorado Springs, CO: SAE.

Schmidt, I., and Bock, E. (1997). Anaerobic ammonia oxidation with nitrogen dioxide by Nitrosomonas eutropha. Arch. Microbiol. 167, 106. 
Schmidt, I., and Bock, E. (1998). Aerobic ammonia oxidation by cell-free extracts of Nitrosomonas eutropha. Antonie van Leeuwenhoek 73, 271.

Schramm, A., Beer, D.D., Gieseke, A., and Amann, R. (2000). Microenvironments and distribution of nitrifying bacteria in a membrane-bound biofilm. Environ. Microbiol. 2, 680.

Sliekers, A.O., Derwort, N., Campos Gomez, J.L., Strous, M. Kuenen, J.G., and Jetten, M.S.M. (2002). Completely autotrophic nitrogen removal over nitrite in one single reactor. Water Res. 36, 2475.

Sliekers, A.O., Third, K.A., Abma, W., Kuenen, J.G., and Jetten, M.S.M. (2003). CANON and anammox in a gas-lift reactor. FEMS Microbiol. Lett. 218, 339.

Sliekers, A.O., Haaijer, S.C.M., Stafsnes, M.H., Kuenen, J.G., and Jetten, M.S.M. (2005). Competition and coexistence of aerobic ammonium- and nitrite-oxidizing bacteria at low oxygen concentrations. Appl. Microbio. Biotechnol. 68, 808.

Smith, D.P., Rector, T., Reid-Black, K., Hummerick, M., Strayer, R., Birmele, M., Roberts, M.S., and Garland, J.L. (2008). Redox control bioreactor: A unique biological water processor. Biotechnol. Bioeng. 99, 830.

Stein, L.Y., Arp, D.J., Berube, P.M., Chain, P.S.G., Hauser, L., Jetten, M.S.M., Klotz, M.G., Larimer, F.W., Norton, J.M., Op den Camp, H.J.M., Shin, M., and Wei, X. (2007). Wholegenome analysis of the ammonia-oxidizing bacterium, $\mathrm{Ni}$ trosomonas eutropha C91: Implications for niche adaptation. Environ. Microbiol. 9, 2993.

Stein, L.Y., and Yung, Y.L. (2003). Production, isotopic composition, and atmospheric fate of biologically produced nitrous oxide. Annu. Rev. Earth Plan. Sci. 31, 329.

Strous, M., Gerven, E.V., Zheng, P., Kuenen, J.G., and Jetten, M.S.M. (1997). Ammonium removal from concentrated waste streams with the anaerobic ammonium oxidation (anammox) process in different reactor configurations. Water Res. 31, 1955.

Tallec, G., Garnier, J., and Gousailles, M. (2006). Nitrogen removal in a wastewater plant through biofilters: Nitrous oxide emissions during nitrification and denitrification. Bioprocess Biosyst. Eng. 29, 323

Terada, A., Hibiya, K., Nagai, J., Tsuneda, S., and Hirata, A. (2003). Nitrogen removal characteristics and biofilm analysis of a membrane-aerated biofilm reactor applicable to highstrength nitrogenous wastewater treatment. J. Biosci. Bioeng. 95, 170.

Terada, A., Yamamoto, T., Hibiya, K., Tsuneda S., and Hirata, A (2004). Enhancement of biofilm formation onto surfacemodified hollow-fiber membranes and its application to membrane-aerated biofilm reactor. Water Sci. Technol. 49, 263.

Terada, A., Yamamoto, T., Igarashi, R., Tsuneda, S., and Hirata, A. (2006). Feasibility of a membrane-aerated biofilm reactor achieve controllable nitrification. Biochem. Eng. J. 28, 123.

Terada, A., Lackner, S., Tsuneda, S., and Smets, B.F. (2007). Redoxstratification controlled biofilm (ReSCoBi) for completely autotrophic nitrogen removal: The effect of co- versus counter-diffusion on reactor performance. Biotechnol. Bioeng. 97, 40.

Terada, A., Lackner, S., Kristensen, K., and Smets, B.F. (2010). Inoculum effects on community composition and nitritation performance of autotrophic nitrifying biofilm reactors with counter-diffusion geometry. Environ. Microbiol. 12, 2858.

Vadivelu, V.M., Keller, J., and Yuan, Z. (2006). Effect of free ammonia and free nitrous acid concentration on the anabolic and catabolic processes of an enriched Nitrosomonas culture. Biotechnol. Bioeng. 95, 830.

Vadivelu, V.M., Keller, J., and Yuan, Z. (2007). Effect of free ammonia on the respiration and growth processes of an enriched Nitrobacter culture. Water Res. 41, 826. 


\section{This article has been cited by:}

1. Yaoli Ye, Pascal E. Saikaly, B.E. Logan. 2017. Simultaneous nitrogen and organics removal using membrane aeration and effluent ultrafiltration in an anaerobic fluidized membrane bioreactor. Bioresource Technology 244, 456-462. [Crossref]

2. Yuli Yang, Xiaojin Li, Xiaoli Yang, Zhen He. 2017. Enhanced nitrogen removal by membrane-aerated nitritation-anammox in a bioelectrochemical system. Bioresource Technology 238, 22-29. [Crossref]

3. Adele Brunetti, Pasquale F. Zito, Lidietta Giorno, Enrico Drioli, Giuseppe Barbieri. 2017. Membrane reactors for low temperature applications: An overview. Chemical Engineering and Processing: Process Intensification . [Crossref]

4. Duoying Zhang, Riku Vahala, Yu Wang, Barth F. Smets. 2016. Microbes in biological processes for municipal landfill leachate treatment: Community, function and interaction. International Biodeterioration \& Biodegradation 113, 88-96. [Crossref]

5. Xiaojin Li, Shan Sun, Brian D. Badgley, Shihwu Sung, Husen Zhang, Zhen He. 2016. Nitrogen removal by granular nitritationanammox in an upflow membrane-aerated biofilm reactor. Water Research 94, 23-31. [Crossref]

6. Robert Nerenberg. 2016. The membrane-biofilm reactor (MBfR) as a counter-diffusional biofilm process. Current Opinion in Biotechnology 38, 131-136. [Crossref]

7. Salman Alizadeh Kordkandi, Ali Baradar Khoshfetrat. 2015. Influence of carbon/nitrogen ratio and non-aerated zone size on performance and energy efficiency of a partially-aerated submerged fixed-film bioreactor. Journal of Industrial and Engineering Chemistry 31, 257-262. [Crossref]

8. Jeseth Delgado Vela, Lauren B. Stadler, Kelly J. Martin, Lutgarde Raskin, Charles B. Bott, Nancy G. Love. 2015. Prospects for Biological Nitrogen Removal from Anaerobic Effluents during Mainstream Wastewater Treatment. Environmental Science \& Technology Letters 2:9, 234-244. [Crossref]

9. Jiayi Lin, Panyue Zhang, Jiang Yin, Xuehao Zhao, Juan Li. 2015. Nitrogen removal performances of a polyvinylidene fluoride membrane-aerated biofilm reactor. International Biodeterioration \& Biodegradation 102, 49-55. [Crossref]

10. Hong Liu, Shuying Tan, Zhiya Sheng, Tong Yu, Yang Liu. 2015. Impact of oxygen on the coexistence of nitrification, denitrification, and sulfate reduction in oxygen-based membrane aerated biofilm. Canadian Journal of Microbiology 61:3, 237-242. [Crossref]

11. Carles Pellicer-Nàcher, Stéphanie Franck, Arda Gülay, Maël Ruscalleda, Akihiko Terada, Waleed Abu Al-Soud, Martin Asser Hansen, Søren J. Sørensen, Barth F. Smets. 2014. Sequentially aerated membrane biofilm reactors for autotrophic nitrogen removal: microbial community composition and dynamics. Microbial Biotechnology 7:1, 32-43. [Crossref] 